\title{
Effects of Repeated Bouts of Exercise on the Hemostatic System
}

\author{
Lisa N. van der Vorm, MSc 1,2,3 Dana Huskens, $\mathrm{PhD}^{1,2}$ Cécile H. Kicken, MD ${ }^{2,4}$ Jasper A. Remijn, PhD ${ }^{1,3}$ \\ Mark Roest, $\mathrm{PhD}^{1,2}$ Bas de Laat, MD, PhD ${ }^{1,2,3}$ Adam Miszta, PhD, MSc Eng ${ }^{1,2,5}$ \\ ${ }^{1}$ Cardiovascular Research Institute Maastricht, Maastricht University \\ Medical Centre, Maastricht University, Maastricht, The Netherlands \\ 2 Synapse Research Institute, Maastricht, The Netherlands \\ ${ }^{3}$ Department of Clinical Chemistry and Hematology, Gelre Hospitals, \\ Apeldoorn, The Netherlands \\ ${ }^{4}$ Department of Anaesthesiology, Maastricht University Medical \\ Centre, Maastricht University, Maastricht, The Netherlands \\ ${ }^{5}$ Department of Pathology and Laboratory Medicine, University of \\ North Carolina at Chapel Hill, Chapel Hill, North Carolina \\ Address for correspondence Adam Miszta, PhD, MSc Eng, \\ Department of Pathology and Laboratory Medicine, University of \\ North Carolina at Chapel Hill, Chapel Hill, NC \\ (e-mail: a.miszta@thrombin.com).
}

Semin Thromb Hemost 2018;44:710-722.

\begin{abstract}
Physical activity is beneficial for health, for example, by lowering the risk of cardiovascular events. However, vigorous exercise is associated with the occurrence of thromboembolic events and sudden cardiac death, in particular in untrained individuals. Whereas acute exercise is known to cause a hypercoagulable state, repeated exposure to (strenuous) exercise by means of training may actually condition the hemostatic response to exercise. To date, the effects of exercise training on blood coagulability and the underlying mechanisms have yet to be fully discerned. In this review, the authors provide an overview of existing literature on how training programs and training status influence hemostasis in healthy individuals. Furthermore, they present data of a pilot study in which we studied the effects of repetitive submaximal intensity cycling on procoagulant and anticoagulant processes. It is known that factor VIII (FVIII) and von Willebrand factor (VWF) increase after exercise, but we found that this increase in FVIII and VWF (antigen, propeptide, and VWF in active conformation) was smaller on each of three subsequent days, suggesting either adaptation of

\section{Keywords}

- physical training

- repetitive exercise

- hemostasis

- coagulation

- fibrinolysis endothelial activation or exhaustion of endothelial VWF supplies. With respect to thrombin generation, elevated FVIII significantly increased the thrombin generation peak but not the endogenous thrombin potential. In contrast, platelet activation in terms of P-selectin expression after stimulation with protease-activated receptor- 1 and glycoprotein $\mathrm{VI}$ agonists decreased after exercise and did not recover, indicating exhaustion of the platelet response to repetitive exercise.
\end{abstract}

Cardiovascular disease remains the leading cause of mortality and morbidity globally. ${ }^{1}$ Regular exercise is essential for a healthy lifestyle, promoting cardiovascular health, as shown by many epidemiological and clinical studies. ${ }^{2-4}$ Several studies have reported an association of increasing physical activity with reduced morbidity and mortality, ${ }^{5,6}$ which can be explained by benefits such as weight loss, lowered blood pressure, and improved lipid profiles and glucose metabolism. ${ }^{7-9}$

Regular physical activity is associated with the prevention of cardiovascular disease, with an effect similar in magnitude ( 30\%) to pharmacological strategies. ${ }^{10}$ However, more physical exercise may not always be better. Indeed, the benefit of published online October 5, 2018
Issue Theme Hemostasis in Exercise and the Athlete; Guest Editors: Murray J. Adams, BSc(Hons), PhD, MAIMS, FFSc(RCPA) and James W. Fell, BEd, MPhil, PhD.
Copyright (c) 2018 by Thieme Medical Publishers, Inc., 333 Seventh Avenue, New York, NY 10001, USA. Tel: +1(212) 584-4662.
DOI https://doi.org/ 10.1055/s-0038-1673619. ISSN 0094-6176. 
exercise is still a subject of debate that is referred to as the "exercise paradox." 11,12 The debate is relevant because there are numerous reports of exercise-related thromboembolic events, such as myocardial infarction, ischemic stroke, and venous thrombosis, ${ }^{13,14}$ and acute exercise is associated with a two- to threefold higher risk of sudden cardiac death. ${ }^{15,16}$

One crucial protagonist of atherosclerotic and atherothrombotic disease is the hemostatic system. ${ }^{17}$ Exercise is known to exert a plethora of effects on hemostasis. These include increased levels of clotting factors (factor VIII [FVIII] and von Willebrand factor [VWF]), platelet count and reactivity, a shortening of the activated partial thromboplastin time (aPTT) $)^{18,19}$ and increased thrombin generation (TG), ${ }^{20}$ as well as increases in fibrinolytic markers (prothrombin fragments $1+2$ and thrombin-antithrombin complexes). ${ }^{21,22}$ Altogether, these changes result in a shift toward a transient hypercoagulable state, $^{23}$ that depends at least partly on exercise intensity. ${ }^{24}$ Whereas moderate exercise enhances fibrinolytic activity, strenuous exercise (corresponding to $80-100 \%$ of the maximal heart rate) induces a more procoagulant state, causing an enhanced risk of thrombotic events, especially in untrained individuals. $^{25-27}$ Contrary to acute high-intensity exercise, regular training at moderate intensity is associated with a lower overall risk of adverse cardiovascular events. ${ }^{28,29}$

The effects of (strenuous) exercise on hemostasis have been reviewed extensively by others. ${ }^{23,26,30}$ Many studies report on the effects of a single bout of vigorous physical activity (either of short or long duration, the latter mostly in marathons). However, it is not a single bout but long-term repeated exercise that results in improved physical fitness which is known to be beneficial for the cardiovascular system $^{31,32}$ and is related to reduced mortality. ${ }^{33,34}$

To date, the effects of repeated bouts of exercise on hemostasis and the underlying mechanisms have yet to be fully discerned, and data on this specific topic is lacking. Therefore, we recently performed a pilot study in which we studied whether repetitive strenuous cycling had an additive, exhaustive, or adaptive effect on changes in procoagulant and antic- oagulant processes (see the -Appendix). More data on the effects of training on these variables are becoming available. This review aims to provide insight of how repeated exercise influences hemostatic parameters (in healthy individuals), by placing it in the context of what is known on the hemostatic effects of training programs and improved training status. We defined "exercise training" as repeated exercise undertaken at a guided or prescribed intensity (either moderate or intensive) and frequency over a specific period of time.

\section{Effects of Exercise Training on Peripheral Blood Cell Counts}

Excessive training in athletes has been associated with increased susceptibility to infections, as a result of chronic imunosuppression. ${ }^{35}$ Furthermore, acute exercise is known to induce peripheral leukocytosis. ${ }^{36}$ This leukocyte response is biphasic: after an immediate transient response of lymphocytosis, monocytosis, and neutrophilia, a delayed response comprising mainly neutrophilia occurs. Longer term exhaustive endurance exercise such as a marathon or triathlon is predominantly associated with this delayed neutrophilia. ${ }^{37,38}$ The proposed mechanism is an increase in the stress hormone cortisol above $60 \%$ of maximum oxygen uptake $\left(\mathrm{VO}_{2} \max \right){ }^{38} \mathrm{~A}$ longitudinal study by Suzuki et $\mathrm{l}^{39}$ addressed the adaptability of these blood cell responses to training. Ten healthy untrained men performed exercise sessions (at an intensity of $70 \%$ of $\mathrm{VO}_{2}$ $\max$ ) for 1.5 hour each day, for 7 consecutive days. Whereas the first training session caused marked peripheral neutrophilia, in particular band neutrophils, the magnitude of the exerciseinduced changes reduced gradually (although not significantly) by daily repeated exposure to endurance exercise. However, none of the trends were significant except the decline in resting segmented neutrophil counts. ${ }^{39}$ In our cycling study (see the -Appendix), we observed a similar cellular response to repeated exercise ( - Fig. 1), characterized by an increase in granulocytes and decrease in monocytes and lymphocytes on the first day after exercise, followed by
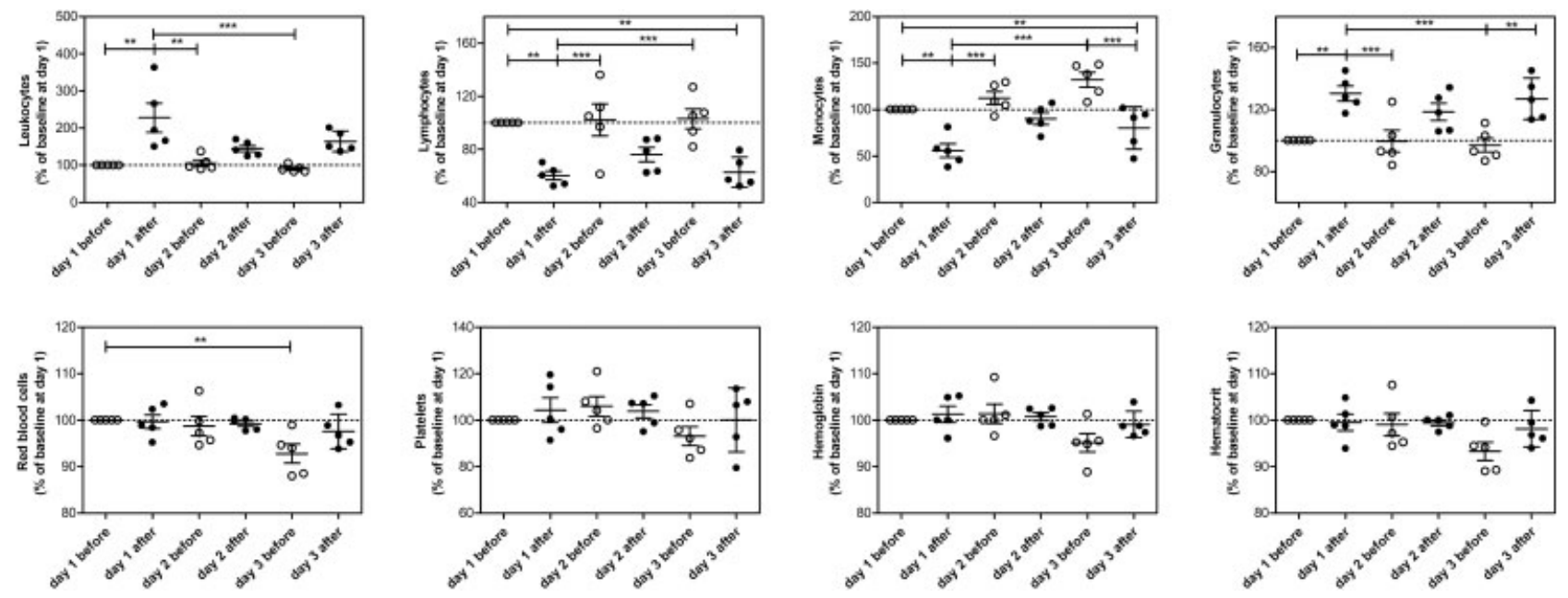

Fig. 1 Exercise-induced lymphocytosis, monocytosis, and neutrophilia. On the first day, the number of granulocytes was significantly increased after cycling. In contrast, monocyte and lymphocyte levels decreased each day after cycling. On the second and third day, levels returned to baseline. Platelets, red blood cell count, hematocrit, and hemoglobin remained largely stable. Data represent the mean \pm standard deviation (SD) $(n=5)$. 
recovery to baseline each day before exercise. On the first day, the number of granulocytes was significantly increased after cycling. On the second and third day, this level returned to baseline, but cycling evoked a smaller increase in granulocyte levels compared with the first day. In contrast, monocyte and lymphocyte levels decreased significantly on day 1 each day after cycling, but also returned to baseline each day before the cycling. Platelets, red blood cell (RBC) count, hematocrit, and hemoglobin remained largely stable.

\section{Effects of Exercise Training on Hemostasis}

- Table 1 provides an overview of studies investigating the effect of training on a variety of hemostatic parameters.

\section{Primary Hemostasis}

\section{Platelet Activity}

Platelet reactivity has a stable association with the occurrence of acute thrombosis and the long-term pathogenesis of thrombosis and cardiovascular diseases. ${ }^{40,41}$ However, the effects of physical training on platelet function have not been fully discerned. It is hypothesized that training in healthy individuals could reduce the risk of cardiovascular disease by suppressing platelet reactivity. Supporting this hypothesis is the observed decrease in exercise-induced platelet hyperreactivity as a result of endurance training in previously sedentary individuals. ${ }^{42-44}$

Two studies investigated the effect of training on platelet activation markers platelet factor 4(PF4) and $\beta$-thromboglobulin

Table 1 Overview of studies and reported (direction of the) effect of training (physically trained compared with sedentary individuals or post- versus pretraining program in the same individual) on hemostatic parameters

\begin{tabular}{|c|c|c|c|c|}
\hline & Parameter & & Effect & Reference \\
\hline \multirow[t]{14}{*}{ Coagulation } & \multirow[t]{5}{*}{ Clotting times } & aPTT & $\downarrow$ & Korsan-Bengtsen et al ${ }^{53}$ \\
\hline & & aPTT & $\uparrow$ & Hilberg et al $^{54}$; Kupchak et al ${ }^{55}$ \\
\hline & & aPTT & $=$ & Ferguson et at ${ }^{50}$ \\
\hline & & PT & $=$ & Ferguson et $\mathrm{al}^{50} ;$ El-Sayed et $\mathrm{al}^{52} ;$ Korsan-Bengtsen et $\mathrm{al}^{53}$ \\
\hline & & TT & $=$ & Watts $^{51}$; El-Sayed et al ${ }^{52}$ \\
\hline & \multirow[t]{2}{*}{ FVIII } & \multirow[t]{2}{*}{$\mathrm{Ag}$} & $\uparrow$ & Lockard et al $^{79}$ \\
\hline & & & $=$ & $\begin{array}{l}\text { Boman et al }{ }^{76} \text {; Watts }{ }^{51} \text {; Rankinen et } a^{77} \text {; Ponjee et al }{ }^{45} ; \\
\text { van den Burg et al }{ }^{78} \text {; Lippi et al }{ }^{64} \text {; Korsan-Bengtsen et al }\end{array}$ \\
\hline & VWF & $\mathrm{Ag} / \mathrm{Act}$ & $\downarrow$ & Wang et $\mathrm{al}^{44}$ \\
\hline & \multirow[t]{3}{*}{ Thrombin } & ETP & $\downarrow$ & Cimenti et al ${ }^{131}$ \\
\hline & & $\mathrm{F} 1+2$ & $\downarrow$ & Hilberg et $\mathrm{al}^{54}$; Lockard et $\mathrm{al}^{79} ;$ Kupchak et $\mathrm{al}^{55}$ \\
\hline & & TAT & $=$ & Kupchak et al $^{55}$ \\
\hline & \multirow[t]{3}{*}{ Fibrinogen } & \multirow[t]{3}{*}{$\mathrm{Ag}$} & $\downarrow$ & El-Sayed $^{90} ;$ Stratton et al ${ }^{85}$ (elderly men) \\
\hline & & & $\uparrow$ & Schuit et al $^{92}$ (elderly men) \\
\hline & & & $=$ & $\begin{array}{l}\text { Stratton et al }{ }^{85} \text { (young men); DeSouza et al } \\
\text { (elderly women); Kupchak et } \mathrm{al}^{55}\end{array}$ \\
\hline \multirow[t]{7}{*}{ Platelets } & \multirow{7}{*}{$\begin{array}{l}\text { Aggregation } \\
\text { Activation }\end{array}$} & & $\downarrow$ & Wang et al $^{44}$ \\
\hline & & P-sel & $\downarrow$ & Santilli et al ${ }^{108}$; Wang et al $^{44}$ \\
\hline & & VWF bind. & $\downarrow$ & Wang et $\mathrm{al}^{44}$ \\
\hline & & \multirow[t]{2}{*}{ PF4 } & $\uparrow$ & Ponjee et al ${ }^{45}$ \\
\hline & & & $=$ & 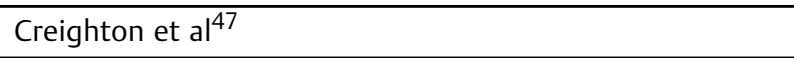 \\
\hline & & $\beta \mathrm{TG}$ & $\downarrow$ & Davis et al $^{42}$; Gonzales et $\mathrm{al}^{46}$; Creighton et al ${ }^{47}$ \\
\hline & & GPIb/GPIV & $\downarrow$ & Kestin et $\mathrm{al}^{43}$ \\
\hline \multirow[t]{5}{*}{ Fibrinolysis } & Clot lysis time & & $=$ & Ferguson et $\mathrm{al}^{50}$; Korsan-Bengtsen et $\mathrm{al}^{53}$ \\
\hline & $\mathrm{tPA}$ & $\mathrm{Ag} / \mathrm{Act}$ & $\uparrow$ & Szymanski et al $^{84}$; De Paz et al ${ }^{100}$; Kupchak et al ${ }^{55}$; \\
\hline & \multirow[t]{3}{*}{ PAI-1 } & \multirow[t]{3}{*}{$\mathrm{Ag}$} & $\downarrow$ & Kulaputana et al $^{125}$ \\
\hline & & & $\uparrow$ & De Geus et al $^{101}$; Gris et al ${ }^{102}$; Kupchak et al ${ }^{55}$; \\
\hline & & & $=$ & 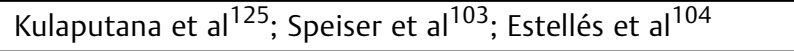 \\
\hline
\end{tabular}

Abbreviations: $=$, no change, in response to physical training/increased training status; $\uparrow$, increase; $\downarrow$, decrease; Act, activity; Ag, antigen; aPTT, activated partial thromboplastin time; $\beta$ TG, $\beta$ thromboglobulin; ETP, endogenous thrombin potential; $F 1+2$, prothrombin fragment 1 and 2; GPIb/ GPIV, glycoprotein Ib/glycoprotein IV; PAI-1, plasminogen activator inhibitor-1; PF4, platelet factor 4; P-sel, P-selectin; PT, prothrombin time; TAT, thrombin-antithrombin complex; tPA, tissue plasminogen activator; TT, thrombin time; VWF bind, von Willebrand factor binding. 
( $\beta T G)$. In a prospective study, a 9-month endurance training program resulted in slightly increased PF4, but no significant change in $\beta$ TG levels in men and women, suggesting unfavorable training-induced in vivo platelet activation. ${ }^{45}$ In contrast, resting $\beta$ TG levels in physically fit individuals have been reported to be lower compared with sedentary controls. ${ }^{42,46}$ Thus, an improved training status appears to have different effects on resting platelet activation than a long-term training program, but further studies in larger populations are warranted to investigate this hypothesis and the underlying mechanism.

In a study by Creighton et al, the hemostatic recovery after exercise in terms of platelet $\beta T G$ and PF4 was monitored with enzyme-linked immunosorbent assays (ELISAs) instead of radioimmunoassays. In the first hour postexercise, resistance-trained individuals displayed significantly reduced platelet activation, in terms of lower $\beta$ TG levels, compared with untrained individuals. ${ }^{47}$ Of note, PF4 and $\beta T G$ radioimmunoassays and ELISAs are associated with some methodological difficulties. ${ }^{43,48}$ An alternative analysis method for platelet activation is whole blood flow cytometry using antibodies against platelet activation markers, for example, glycoprotein (GP) Ib and GPIV. Using this assay, strenuous exercise was found to induce both platelet activation and platelet hyperreactivity in sedentary subjects but not in physically trained subjects. ${ }^{43}$

In our cycling study, platelet activation was also measured in whole blood with a flow-cytometric platelet function test (-Fig. 2). ${ }^{49}$ Granule release potential was measured as P-selectin expression and the aggregation potential was measured as activation of the $\alpha$ IIb $\beta 3$ receptor, both after adding the platelet agonists thrombin receptor-activating peptide (TRAP), collagen-related peptide (CRP), or 2-methylthio-adenosine diphosphate (Mes-ADP). Postcycling, P-selectin expression showed a similar decreasing pattern for protease-activated receptor-1 (PAR-1) stimulation by TRAP and GPVI stimulation by CRP. Interestingly, there was no recovery to baseline the next day before cycling, and P-selectin expression in response to these agonists dropped significantly on the third day. In contrast, $\alpha I \mathrm{Il} \beta 3$ expression increased slightly after exercise but decreased to baseline for PAR-1, or even lower than baseline for GPVI, on the next day prior to exercise. Mes-ADPmediated P2Y12 stimulation induced increased P-selectin expression and $\alpha \mathrm{IIb} \beta 3$ activation the first day after exercise, but remained rather stable on the subsequent days. In summary, repeated exercise predominantly induced an exhaustive effect on platelet granule secretion (P-selectin expression) in response to TRAP and CRP.

\section{Clotting Times}

The conventional prothrombin time (PT) and aPTT are measures of overall plasma coagulation via different pathways, and measure the time needed for clot formation; a shortened clotting time indicates a prothrombotic state, whereas increased clotting time indicates hypocoagulability. The PT and aPTT were not different between joggers, marathon runners, and individuals with a sedentary lifestyle, both at rest and after exercise. ${ }^{50}$ These findings are in accordance with a later study reporting a similar thrombin time (TT) at rest in athletes and nonathletic individuals. ${ }^{51}$ Moreover, one of the few longitudinal studies investigating the long-term effects of training on coagulation demonstrated no significant change in TT and PT after 3 months of endurance training. ${ }^{52}$ However, although it can be debated whether daily physical activity can be considered training, a large cohort study including 772 men (all aged 54 years) found
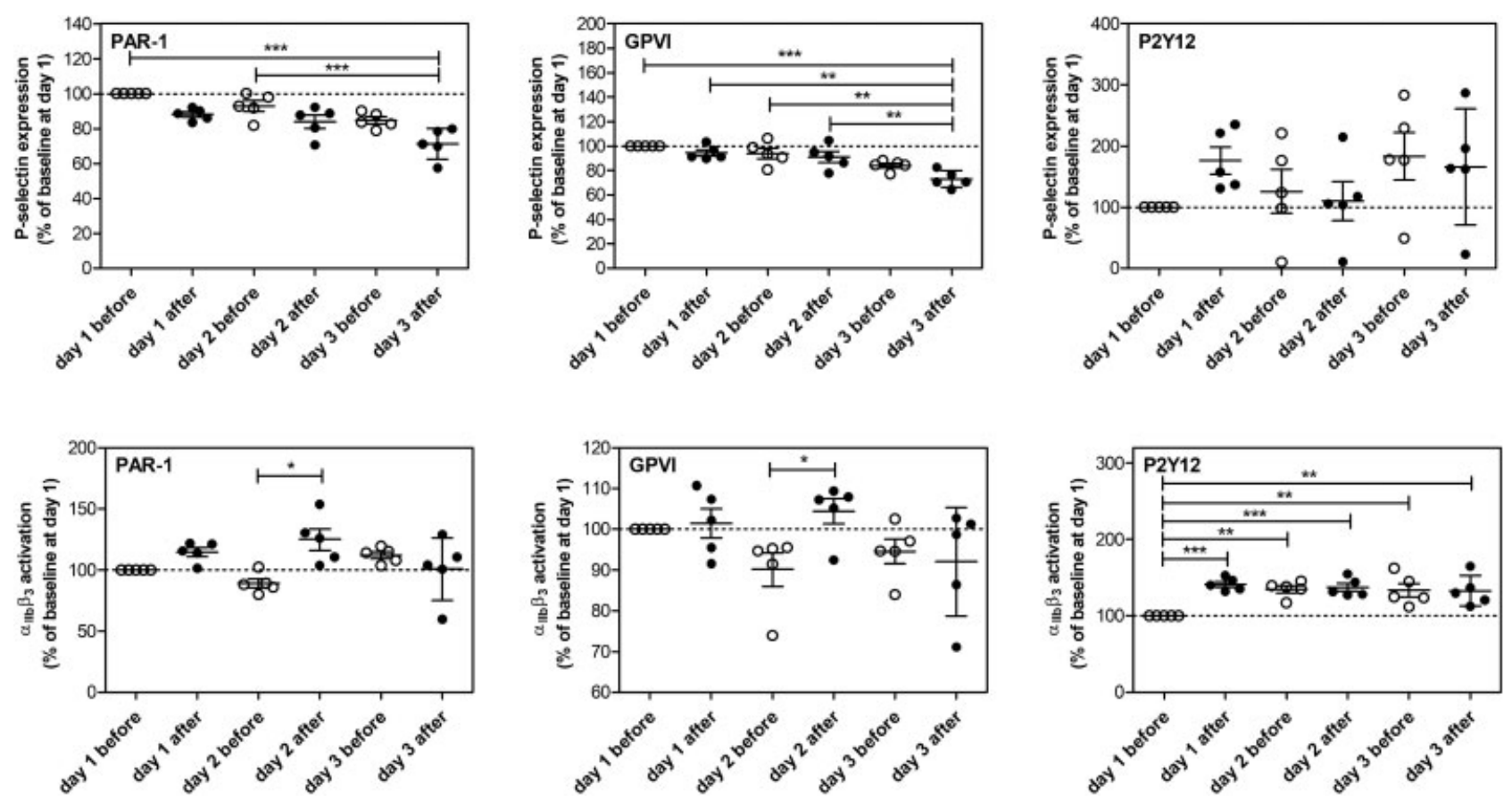

Fig. 2 Repetitive exercise induces exhaustion of the P-selectin expression in response to protease-activated receptor (PAR)-1 and glycoprotein (GP) IV agonists. Data are presented as mean \pm standard deviation (SD) $(n=5)$. 
that physically very active individuals (assessed by a questionnaire) did have a significantly lower aPTT, indicative of a hypercoagulable state, compared with nonactive individuals. ${ }^{53}$ In contrast, one of the few randomized controlled studies found a small but significant prolongation of the aPTT, meaning a more hypocoagulable state, at rest and postexercise after 12 weeks of moderate aerobic endurance training. ${ }^{54}$ The latter was confirmed by a more recent study in which trained subjects had a lower clot-forming capacity (prolonged aPTT) following an acute exhaustive resistance exercise test than untrained subjects. ${ }^{55}$ Taken together, data on the effects of training on clotting times are inconclusive. Of note, both PT and aPTT are relatively "crude" screening tests that may not be sensitive enough to detect hypercoagulability. Therefore, further studies should focus on more sensitive biomarkers of coagulation.

\section{von Willebrand Factor}

von Willebrand factor is a large multimeric plasma GP with essential functions in hemostasis. ${ }^{56}$ Several agonists, including hypoxia, epinephrine, histamine, thrombin, fibrin, and vasopressin, trigger release of hyperreactive ultra-large VWF multimers from endothelial cell Weibel-Palade bodies. ${ }^{57,58}$ Importantly, this endothelial cell activation also occurs after both short-duration exhaustive exercise ${ }^{30}$ and long-duration vigorous exercise, ${ }^{16-18}$ resulting in an increase in circulating VWF levels.

In our cycling study in five healthy and physically fit individuals, all VWF parameters (VWF antigen [VWF:Ag], VWF propeptide [VWF:pp], and active VWF) were significantly increased on the first day after cycling (-Fig. 3A-C). It is well known that levels of VWF:Ag increase steeply upon acute intense physical exercise. ${ }^{59}$ Also, several studies demonstrated exercise-induced elevation of VWF activity, as measured by collagen-binding assays ${ }^{60}$ or ristocetin cofactor assays. ${ }^{61}$ However, not many studies have determined VWF:pp and active VWF (see the - Appendix) levels in response to exercise. VWF:pp is critical for intracellular processing of VWF by endothelial cells. It was previously established that by assaying both VWFpp and VWF:Ag, one
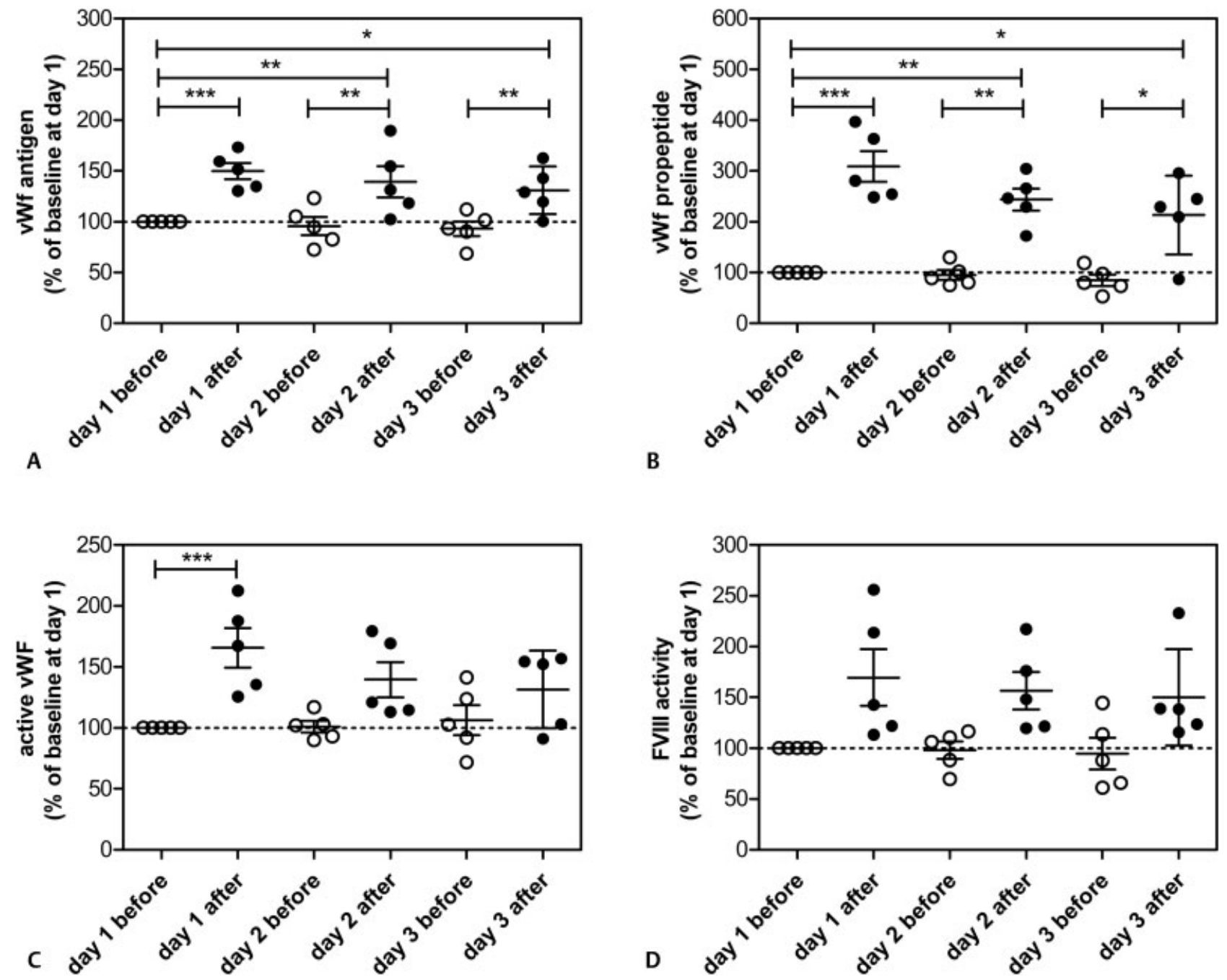

Fig. 3 Repetitive exercise induces an endothelial adaptive response. The magnitude of the exercise-induced increase in (A) von Willebrand factor (VWF) antigen (VWF:Ag), (B) VWF propeptide (VWF:pp), (C) active VWF, and (D) factor VIII (FVIII) is less every subsequent day after cycling. (D) FVIII activity was measured as described previously. ${ }^{126,127}$ All measurements were performed in triplicate, and data represent the mean \pm standard deviation (SD) $(n=5)$. 
can distinguish between acute and chronic endothelial cell damage. ${ }^{48}$ In healthy controls, a concomitant rise of VWF:pp and VWF:Ag levels, for example, after exercise-induced release from endothelial cell storage, is followed by a rapid decline in VWF:pp level, whereas VWF:Ag levels return to baseline more slowly. ${ }^{62}$ Active VWF level increases as a result of strenuous exercise due to high intravascular shear stress, which induces VWF to unfold and expose the A1 domain; this conformation is known as active VWF. The observed postexercise increase in active VWF is in accordance with those reported for the healthy control group in a study on the effects of exercise on VWF in type 1 and type 2B von Willebrand disease patients. ${ }^{61}$ In our cycling study, on the second and third day before cycling all VWF parameters had returned to baseline. Strikingly, on these days all VWF parameters on average increased slightly less in response to cycling compared with the effect on the first day, suggesting that already within 3 days either exhaustion of the endothelial response to physical stress or exhaustion of the VWF supply, similar to tachyphylaxis after repeated DDAVP administration, can be observed. In line with this, the endothelium is known for being modifiable depending on its environment, by mediating pro- and anticoagulant systems. In fact, a previous study demonstrated that nitric oxide (NO)-dependent endothelial functions can adapt favorably in as little as 1 week of endurance training. ${ }^{63}$

Conflicting data are reported on the effect of training status on VWF levels. While VWF:Ag levels did not differ between professional cyclists and sedentary individuals, ${ }^{64}$ the increase in VWF:Ag upon strenuous exercise appears strongly dependent on performance (among others peak power output $/ \mathrm{kg}$ body weight and $\mathrm{VO}_{2}$ peak $/ \mathrm{kg}$ ) and physical fitness-related determinants (among others $\mathrm{VO}_{2}$ at ventilatory threshold and power output at ventilatory threshold). Interestingly, this increase in VWF:Ag level upon strenuous exercise was highest in individuals who are the least physically fit but also in those who regularly performed very highintensity exercise. ${ }^{60}$ In a cohort of equally physically fit subjects, an 8-week training program reduced levels of resting and postexercise VWF:Ag and activity. However, deconditioning completely reverses this training effect. ${ }^{65}$

From a mechanistic point of view, VWF:Ag stored in Weibel-Palade bodies of endothelial cells and platelets may be released more rapidly: (1) as a result of traininginduced upregulation of $\beta 2$-adrenoreceptors, ${ }^{66}$ and (2) to compensate for shear stress induced by agonists such as thrombin, collagen, ${ }^{67}$ epinephrine, ${ }^{68}$ and vasopressin. ${ }^{69}$ For instance, vasopressin increases blood pressure and vascular resistance during exercise, thereby increasing shear stress. Strenuous physical exercise also results in recruitment of capillaries in muscles and an increase in vascular conductance in these muscles. ${ }^{70}$ As a consequence, the endothelium of trained individuals is exposed to more shear stress and more adrenergic stimulation, which may explain the increased release of VWF upon exercise. ${ }^{71}$ of note, shear stress is also known to unfold VWF multimers, exposing the A1 domain. ${ }^{72}$ This active conformation of VWF can more readily bind platelets and is thus more thrombogenic. ${ }^{73,74}$
In conclusion, exposure to exercise in trained individuals may facilitate a more rapid return of hemostatic parameters such as VWF to resting conditions. Hence, if this hypothesis would hold true, the release of VWF:Ag may be briefer in trained subjects. $^{75}$

\section{Secondary Hemostasis}

\section{Factor VIII}

Resting levels of FVIII activity and FVIII antigen do not change with training in physically fit, ${ }^{51}$ as well as sedentary individuals in the majority of studies. ${ }^{45,52,64,76-78}$ In a more recent study, FVIII:Ag levels did increase significantly with training, ${ }^{79}$ consistent with the observed increase in FVIII activity after acute exercise. ${ }^{25,30,80,81}$ However, this inconsistency may be explained by population differences, as the latter study included elderly men and women (50-75 years), whereas all other studies mentioned previously were performed with young individuals. In our cycling study, the submaximal intensity cycling induced an increase in FVIII activity on each of three subsequent days (-Fig. 3D). Interestingly, the difference between pre- and postexercise FVIII levels became smaller every day, indicating either adaptation of the FVIII response to exercise or exhaustion of the FVIII supplies. FVIII circulates in complex with VWF, therefore high FVIII levels correlate with an increased level of VWF. Of note, the aforementioned shortening of the aPTT and the elevation in FVIII activity induced by acute strenuous exercise are both indicators for contact factor-mediated clotting activity. Hence, this pathway may have an important role in postexercise hypercoagulability, ${ }^{82}$ but does not appear subject to an adaptive response induced by training.

\section{Thrombin}

In contrast to global clotting assays such as the PT and aPTT, measurement of TG allows assessment of the full process of coagulation over time, providing greater sensitivity. ${ }^{83}$ Thrombin formation is lower in trained versus sendentary subjects as shown by a lower resting endogenous thrombin potential (ETP) ${ }^{84}$ and lower level of prothrombin fragments $\mathrm{F} 1+2$, a surrogate thrombin marker. ${ }^{79}$ In addition, in endurance-trained subjects the increase of thrombin formation in response to exercise is less pronounced compared with controls. 85

Regarding the short-term effect of repetitive exercise on TG, we observed in our cycling study that peak TG was significantly increased on the first day following exercise (-Fig. 4A). However, peak TG returned back to baseline before cycling on the second and third day. This is in accordance with findings from a recent study in which an acute bout of high-intensity exercise increased TG immediately after exercise, but returned to baseline the following day. ${ }^{20}$ Remarkably, almost no increase in ETP was observed after cycling on the second and third day. The ETP before exercise actually decreased over the 3 days of cycling (-Fig. 4B). Together, these results show an initial surge, followed by exhaustion of the thrombin-generating capacity of the hemostatic system. This pattern possibly reflects the 

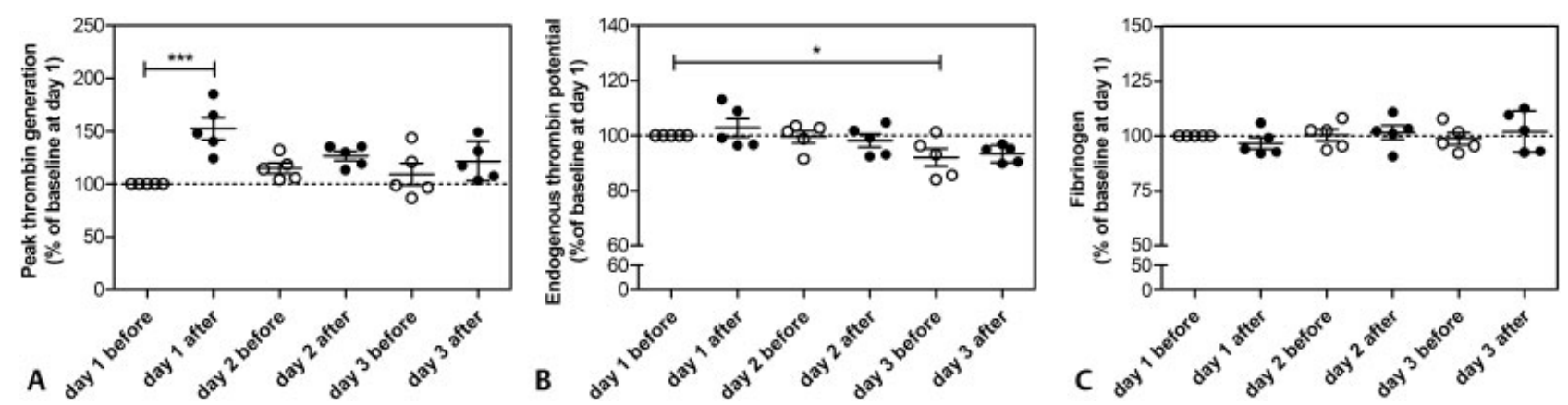

Fig. 4 Repetitive exercise induces an adaptive response of the thrombin generation peak (A) and exhaustion of the endogenous thrombin potential (ETP) (B), but does not affect fibrinogen levels (C). Thrombin generation parameters recorded were peak thrombin (panel A) and ETP (panel B). Data are presented as the mean \pm standard deviation (SD) $(n=5)$.

observed exercise-induced increase in FVIII with a tapered effect over the 3 days. Our study only lasted 3 days, but these results warrant further investigations to determine whether the drop in TG continues further and how much time after exhaustion is required for TG to return to baseline.

Overall, the apparent favorable effect of training on clotting potential may explain the lower incidence of thrombosis in physically fit individuals, despite the transiently hypercoagulable state during and directly after strenuous exercise.

\section{Fibrinogen}

Fibrinogen plays a pivotal role in normal hemostasis, representing the substrate for conversion to fibrin and supporting TG and platelet aggregation. ${ }^{86}$ Studies on the effects of exercise on fibrinogen levels have produced conflicting data, reporting significant increases, decreases, or no effects. ${ }^{30,80,84,87-89}$ These inconsistencies in the literature can likely be attributed to differences in experimental design, including duration, mode and intensity of exercise, health and training status of the study population, and analytical methods. ${ }^{30,80,87}$ Whereas most studies determined the effects of acute exercise, the influence of physical training on plasma fibrinogen levels is less well studied. Cross-sectional studies suggest a favorable effect of regular physical activity, decreasing plasma fibrinogen levels. ${ }^{90,91}$ However, longitudinal data are sparse and conflicting. Physical training at moderate intensity reduced plasma fibrinogen levels in elderly men but not in young men. ${ }^{85}$ In contrast, following intensive training plasma fibrinogen levels were increased in elderly men, paralleled by a surge in C-reactive protein suggesting a chronic increase in acute-phase reactant proteins. ${ }^{92}$ In elderly women, on the other hand, no significant effects of training on fibrinogen levels were found. ${ }^{93} \mathrm{Simi}-$ larly, in our cycling study in men, no significant changes in fibrinogen plasma levels in response to repeated bouts of submaximal exercise were observed ( - Fig. 4C). Altogether, there is a lack of conclusive evidence on the exact effects of physical training on plasma fibrinogen levels.

\section{Fibrinolysis}

In spite of the hypercoagulable state that occurs during and directly after strenuous exercise, regular physical activity has been associated with a reduction in cardiovascular risk. ${ }^{94-96}$ The underlying mechanisms of this conditioning effect remain speculative, but are often ascribed to favorable effects on fibrinolysis. ${ }^{52,97-99}$ However, as with the effects on coagulation, studies on the effects of training on fibrinolysis parameters have produced inconsistent results. Global assays of fibrinolysis, for example, the clot lysis time, found no difference in fibrinolytic capacity between marathon runners and less active individuals. ${ }^{50,53}$ In our small-scale cycling study, clot lysis time decreased only very slightly on the first 2 days after exercise and decreased significantly on the third day (-Fig. 5). When assaying specific fibrinolytic factors, effects of exercise could be observed. For instance, inactive individuals have higher tissue plasminogen activator (tPA) activity and tPA antigen levels compared with active individuals. ${ }^{84,100}$ Data on plasminogen activator inhibitor (PAI)-1 levels following training are inconclusive. A favorable reduction in PAI-1 activity was observed after 8 months of training (albeit not significant due to large group variances and seasonal variations) ${ }^{101}$ and after 3 months of training. ${ }^{102}$ Detraining for 3 months in the latter study reversed the reduction in PAI- 1 activity. ${ }^{102}$ On the other hand, PAI- 1 values were increased in athletes compared with age-

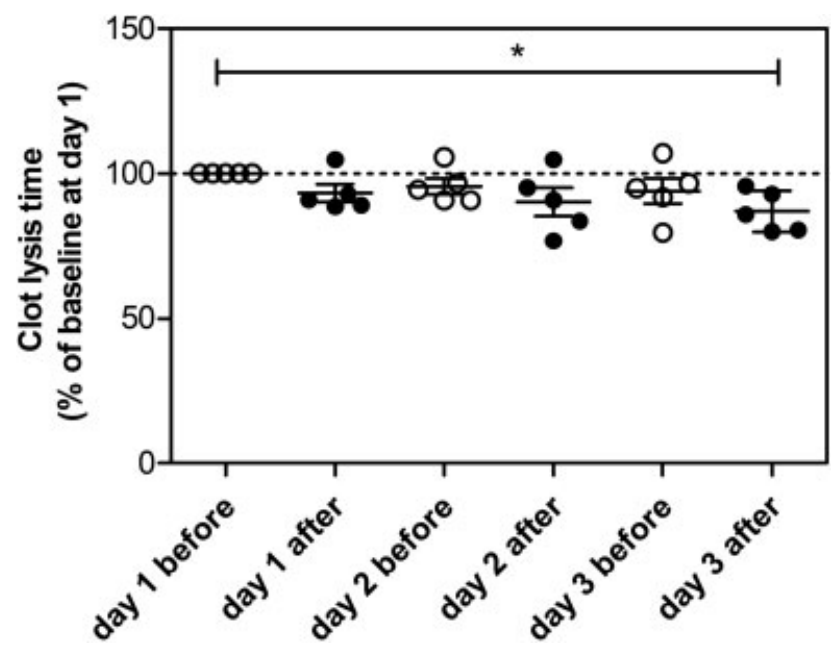

Fig. 5 Repetitive exercise causes only a minor decrease of clot lysis time (CLT) over the course of 3 days. The CLT (50\% fibrinolysis) is defined as the time between maximal and half-maximal turbidity. Data are presented as mean \pm standard deviation (SD) $(n=5)$. 
matched sedentary individuals and elderly sportsmen ${ }^{103}$ and an exercise rehabilitation program did not significantly reduce PAI-1 levels in healthy controls. ${ }^{104}$

Several mechanisms may be responsible for traininginduced adaptation of fibrinolysis. One explanation is the enhanced sensitivity of the endothelium to release tPA, possibly paralleled by reduced clearance of tPA by the liver. In addition, formation of tPA/PAI- 1 complexes is reduced, ${ }^{100,105}$ which may be related to exercise-induced changes in lipid profile that lower resting PAI-1 activity. ${ }^{80,106,107}$ Catecholamines may also play a role in training-related changes in fibrinolysis through their effects on the endothelium. However, data on the magnitude of the effect of plasma epinephrine and norepinephrine are equivocal, and hence the enhanced sensitivity of the endothelium to release tPA may be related to other, nonadrenergic mechanisms.

In conclusion, although the available evidence is derived from highly heterogeneous study protocols, training may have a positive influence on fibrinolysis in terms of an increase in tPA levels and a reduction in PAI-1 levels, although this must be verified in future studies before a definitive conclusion can be drawn.

\section{Modifiers of the Effects of Training on Hemostasis}

\section{Lipid Profile and Nitric Oxide}

Changes in lipid profile and plasma NO levels (as measured by NO metabolites) may modulate platelet reactivity in trained subjects. ${ }^{44}$ Intensive repeated exercise resulted in significantly decreased thromboxane (TX)-dependent platelet activation (urinary excretion of 11-dehydroTXB2, enzymatic metabolite of TXA2), TX-independent platelet activation (plasma P-selectin), and platelet-derived inflammatory proteins (plasma CD40L) in otherwise sedentary subjects. Concomitantly, a significant increase in high-density lipoprotein (HDL) cholesterol concentration, linearly and inversely related to changes in the P-selectin and CD40L platelet activation markers, was observed. ${ }^{108}$ Indeed, HDL is known to engage in a large number of beneficial activities at the endothelial level, among others stimulating NO synthase and inhibiting platelet activation and aggregation, ${ }^{109}$ which may explain mechanistically how this type of high-intensity regular physical training may reduce the risk of cardiovascular events. ${ }^{110}$

\section{Catecholamines}

Regular exercise and training decreases surges in catecholamines, both at rest and following exercise. ${ }^{26}$ Only 1 week of vigorous exercise training was sufficient to induce significant reductions in the norepinephrine response to the same workload. ${ }^{111}$ However, catecholamines have distinct effects on different key players in blood coagulation. For example, training reduces the density and affinity of platelet surface adrenergic receptors. Together with a decreased release of catecholamines in response to exercise, this leads to reduced overall platelet activity and aggregation under high shear flow. ${ }^{112,113}$ In contrast, training-induced upregulation of endothelial $\beta 2$-adrenoreceptors causes accelerated release of FVIII and VWF, ${ }^{66}$ which may result in a more procoagulant phenotype after training.

\section{Dehydration}

During exercise, sweating and intravascular fluid shifts into the interstitium resulting in decreased plasma volume without a proportional loss of plasma proteins. ${ }^{114}$ This hemoconcentration may result in increased postexercise (coagulation) protein levels (falsely suggesting increased activation of the coagulation system) and changes in RBC count, hemoglobin, and hematocrit. ${ }^{114}$ However, whereas in most studies on the effects of short-term exercise plasma volume was decreased after exercise, coagulation factor levels did not change. ${ }^{115-117}$ In one report, an increased hematocrit was accompanied by increased levels of FIX, FXI, and FXII, but no changes in other coagulation factors were observed, suggesting actual activation of the contact pathway of coagulation. ${ }^{25}$ In our cycling study, no changes in hematocrit and hemoglobin and a minor decrease in RBC count were observed. Hence, hemoconcentration is not expected to distort our findings of increased FVIII levels, TG, and VWF following exercise.

\section{Training Status and Mode}

One factor that modifies the effect of physical activity on fibrinolysis is the training status of the individual. ${ }^{50}$ The activating effects of exercise on hemostasis appear more pronounced in sedentary compared with physically fit individuals. ${ }^{59}$ For instance, strenuous exercise caused significant platelet hyperactivation in sedentary men, but not in regularly exercising subjects. ${ }^{43,111}$ Likewise, posttraining tPA release was increased and tPA/PAI-1 complex decreased in physically trained subjects compared with untrained individuals. ${ }^{84,100}$ Training status influences an individual's maximal aerobic capacity, and studies have found that the level of acceleration of fibrinolytic activity is directly related to the workload, suggesting that higher aerobic fitness may lead to a larger increase in fibrinolysis with maximal exercise. ${ }^{50,80}$ Exercise mode may also influence the hemostatic response to training. Above-mentioned studies show that endurance training seems to condition platelets to become less activated and aggregate less in response to strenuous exercise. $^{43,44}$ In contrast, resistance training is believed to enhance hemostatic functions by increasing vessel diameter and promoting antithrombotic endothelial activity. ${ }^{118-121}$

\section{Age}

The favorable effects of training on blood fibrinolysis may be at least partly dependent on age. In the elderly, there is a higher fibrinolytic capacity, characterized by increased tPA and decreased PAI-1 activity ${ }^{85}$ and antigen ${ }^{92}$ after training, compared with young individuals. However, another study reported that physical training can also positively influence blood fibrinolysis in younger individuals. ${ }^{78}$ In addition, plasma fibrinogen levels reduced in response to training in older individuals, but not in young subjects. ${ }^{59,85}$ Other studies have found improvements in hemostatic markers, including PT, FVIII, prothrombin F1 +2 , and VWF in subjects between 50 and 75 years old but not in a younger population. ${ }^{122,123}$ 


\section{Gender}

Most studies examining the hemostatic effects of training included only male subjects. The response of peripheral blood cell counts and D-dimer levels to a single bout of exercise appear the same in both genders, whereas the postexercise clotting times decreased more in males than females. ${ }^{124}$ The sparse data available for repetitive exercise suggests that gender may modulate the fibrinolytic response to training, as endurance training-induced improvements in endogenous fibrinolysis markers, that is, a decrease in PAI-1 and increase in tPA levels, are somewhat greater in men compared with women. ${ }^{125}$

\section{Conclusion}

Although exercise is established to be essential for a healthy lifestyle, there are many reports of exercise-induced thrombotic events. This so-called exercise paradox ${ }^{11,12}$ reflects the complex interplay between hemostasis and physical stress. Whereas the risk of a cardiovascular event after vigorous exercise is increased in untrained individuals, training might induce adaptations of the hemostatic system, explaining its favorable effects on cardiovascular health and mortality.

Primary and secondary hemostasis, as well as fibrinolysis are all affected by training. However, the exact effects of exercise and training on the hemostatic profile and the underlying mechanisms remain to be elucidated. Inconsistencies in reported data, as apparent from - Table 1, can be attributed to variation in subject-related factors such as age, gender, diet, and training status, as well as activity-related factors such as intensity, duration, and mode of exercise. While the latter factors can be standardized by investigators, study populations are generally heterogeneous, precluding definite conclusions on the size and direction of the effects of repeated exercise on pro- and anticoagulant processes.

Furthermore, almost no data on the short-term effects of repeated exercise are reported in the literature. For this reason, we performed a pilot study in which five individuals cycled at submaximal intensity for three subsequent days. The results of this pilot study suggest that repeated submaximal exercise leads to exhaustion of several components of the hemostatic system, predominantly of the endothelium (apparent from changes in VWF and FVIII) and platelet granule secretion (as measured by P-selectin expression).

We acknowledge several limitations of our pilot study that could have influenced the measured hemostatic parameters. First of all, the limited reproducibility of our "exercise protocol," that is, cycling a specific route in the hilly landscape in the south of the Netherlands, and the inability to monitor and control exercise intensity or environmental conditions are important weaknesses of this study. Therefore, in further studies it is recommended to perform a standardized submaximal exercise protocol on a cycling ergometer. In addition, participants were considered physically fit based on their selfreported frequency and intensity of exercise, but this was not objectively determined (e.g., in terms of aerobic capacity $\mathrm{V}_{\mathrm{O} 2}$ max) prior to the pilot study. Thus, observed differences in hemostatic response to bouts of strenuous exercise may be partially accounted for by differences in baseline fitness. Finally, participants consumed water, bananas, energy drinks, energy bars, and energy gels ad libitum during cycling, but the individual fluid and food intake was not recorded.

Several questions related to the effects of repetitive exercise and hemostasis remain unanswered and warrant further investigation. For instance, there is a large gap in knowledge on the effects of training on a crucial factor in fibrinolysis, namely, plasminogen levels and subsequent plasmin generation. Moreover, it is highly relevant to obtain better estimates of the impact of training status on the incidence of exercise-induced thrombotic events, and how this compares to the effects of therapeutic intervention. Ideally, these studies should include a longitudinal design with a follow-up of several years. In addition, new research should focus on biomarkers of training-induced endothelial activation, in particular (active) VWF. Finally, more studies on short-term repetitive exercise on hemostasis are required, as the effects on hemostasis appear different than those induced by long-term repetitive exercise in the form of training. Altogether, insights into the effects of training on hemostatic disturbances by exercise will form the basis to make the double-edged sword of exercise cut in the favorable direction, protecting against thromboembolic morbidity and mortality.

\section{Conflicts of Interest}

None.

\section{Acknowledgments}

We would like to thank the volunteers for their participation in this study and Suzanne Zwaveling, Martijn Moorlag, and Viola Strijbis for their help with blood collection and experiments.

\section{References}

1 World Health Organization (WHO) fact sheet cardiovascular disease. Available at: http://www.who.int/mediacentre/factsheets/fs317/en/. Accessed March 28, 2017

2 Shiroma EJ, Lee IM. Physical activity and cardiovascular health: lessons learned from epidemiological studies across age, gender, and race/ethnicity. Circulation 2010;122(07):743-752

3 Lavie CJ, Thomas RJ, Squires RW, Allison TG, Milani RV. Exercise training and cardiac rehabilitation in primary and secondary prevention of coronary heart disease. Mayo Clin Proc 2009;84 (04):373-383

4 Pollock ML, Franklin BA, Balady GJ, et al. AHA Science Advisory. Resistance exercise in individuals with and without cardiovascular disease: benefits, rationale, safety, and prescription: an advisory from the Committee on Exercise, Rehabilitation, and Prevention, Council on Clinical Cardiology, American Heart Association; Position paper endorsed by the American College of Sports Medicine. Circulation 2000;101(07):828-833

5 Swift DL, Lavie CJ, Johannsen NM, et al. Physical activity, cardiorespiratory fitness, and exercise training in primary and secondary coronary prevention. Circ J 2013;77(02):281-292

6 Kopperstad Ø, Skogen JC, Sivertsen B, Tell GS, Sæther SM. Physical activity is independently associated with reduced mortality: 15years follow-up of the Hordaland Health Study (HUSK). PLoS One 2017;12(03):e0172932 
7 Lippi G, Schena F, Salvagno GL, Montagnana M, Ballestrieri F, Guidi GC. Comparison of the lipid profile and lipoprotein(a) between sedentary and highly trained subjects. Clin Chem Lab Med 2006;44(03):322-326

8 Swift DL, Johannsen NM, Lavie CJ, Earnest CP, Church TS. The role of exercise and physical activity in weight loss and maintenance. Prog Cardiovasc Dis 2014;56(04):441-447

9 Little JP, Francois ME. High-intensity interval training for improving postprandial hyperglycemia. Res Q Exerc Sport 2014;85(04):451-456

10 Thijssen DH, Tinken TM, Hopkins N, Dawson EA, Cable NT, Green DJ. The impact of exercise training on the diameter dilator response to forearm ischaemia in healthy men. Acta Physiol (Oxf) 2011;201(04):427-434

11 Maron BJ. The paradox of exercise. N Engl J Med 2000;343(19): 1409-1411

12 Parto P, O'Keefe JH, Lavie CJ. The exercise rehabilitation paradox: less may be more? Ochsner J 2016;16(03):297-303

13 Albert CM, Mittleman MA, Chae CU, Lee IM, Hennekens CH, Manson JE. Triggering of sudden death from cardiac causes by vigorous exertion. N Engl J Med 2000;343(19):1355-1361

14 Lippi G, Maffulli N. Biological influence of physical exercise on hemostasis. Semin Thromb Hemost 2009;35(03):269-276

15 Schmied C, Borjesson M. Sudden cardiac death in athletes. J Intern Med 2014;275(02):93-103

16 Thompson PD, Franklin BA, Balady GJ, et al; American Heart Association Council on Nutrition, Physical Activity, and Metabolism; American Heart Association Council on Clinical Cardiology; American College of Sports Medicine. Exercise and acute cardiovascular events placing the risks into perspective: a scientific statement from the American Heart Association Council on Nutrition, Physical Activity, and Metabolism and the Council on Clinical Cardiology. Circulation 2007;115(17): 2358-2368

17 Borissoff JI, Spronk HM, ten Cate H. The hemostatic system as a modulator of atherosclerosis. N Engl J Med 2011;364(18): $1746-1760$

18 Hilberg T, Prasa D, Stürzebecher J, Gläser D, Gabriel HHW. Thrombin potential and thrombin generation after exhaustive exercise. Int J Sports Med 2002;23(07):500-504

19 Gunga HC, Kirsch K, Beneke R, et al. Markers of coagulation, fibrinolysis and angiogenesis after strenuous short-term exercise (Wingate-test) in male subjects of varying fitness levels. Int J Sports Med 2002;23(07):495-499

20 Sedgwick MJ, Thompson M, Garnham J, et al. Acute high-intensity interval rowing increases thrombin generation in healthy men. Eur J Appl Physiol 2016;116(06):1139-1148

21 Hilberg T, Prasa D, Stürzebecher J, Gläser D, Schneider K, Gabriel HH. Blood coagulation and fibrinolysis after extreme short-term exercise. Thromb Res 2003;109(5-6):271-277

22 Weiss C, Bierhaus A, Kinscherf R, et al. Tissue factor-dependent pathway is not involved in exercise-induced formation of thrombin and fibrin. J Appl Physiol (1985) 2002;92(01):211-218

23 Posthuma JJ, van der Meijden PE, Ten Cate H, Spronk HM. Shortand long-term exercise induced alterations in haemostasis: a review of the literature. Blood Rev 2015;29(03):171-178

24 Zadow EK, Kitic CM, Wu SSX, Fell JW, Adams MJ. Time of day and short-duration high-intensity exercise influences on coagulation and fibrinolysis. Eur J Sport Sci 2018;18(03):367-375

25 Menzel K, Hilberg T. Blood coagulation and fibrinolysis in healthy, untrained subjects: effects of different exercise intensities controlled by individual anaerobic threshold. Eur J Appl Physiol 2011;111(02):253-260

26 Wang JS. Exercise prescription and thrombogenesis. J Biomed Sci 2006;13(06):753-761

27 Siscovick DS, Weiss NS, Fletcher RH, Lasky T. The incidence of primary cardiac arrest during vigorous exercise. N Engl J Med 1984;311(14):874-877
28 Wang JS, Jen CJ, Kung HC, Lin LJ, Hsiue TR, Chen HI. Different effects of strenuous exercise and moderate exercise on platelet function in men. Circulation 1994;90(06):2877-2885

29 Eijsvogels TM, George KP, Thompson PD. Cardiovascular benefits and risks across the physical activity continuum. Curr Opin Cardiol 2016;31(05):566-571

30 El-Sayed MS, El-Sayed Ali Z, Ahmadizad S. Exercise and training effects on blood haemostasis in health and disease: an update. Sports Med 2004;34(03):181-200

31 Stewart KJ. Exercise training and the cardiovascular consequences of type 2 diabetes and hypertension: plausible mechanisms for improving cardiovascular health. JAMA 2002;288(13): 1622-1631

32 Yoshikawa D, Ishii H, Kurebayashi N, et al. Association of cardiorespiratory fitness with characteristics of coronary plaque: assessment using integrated backscatter intravascular ultrasound and optical coherence tomography. Int J Cardiol 2013; 162(02):123-128

33 Blair SN, Kohl HW III, Barlow CE, Paffenbarger RS Jr, Gibbons LW, Macera CA. Changes in physical fitness and all-cause mortality. A prospective study of healthy and unhealthy men. JAMA 1995; 273(14):1093-1098

34 Kokkinos P, Myers J, Faselis C, et al. Exercise capacity and mortality in older men: a 20-year follow-up study. Circulation 2010;122(08):790-797

35 Gunzer W, Konrad M, Pail E. Exercise-induced immunodepression in endurance athletes and nutritional intervention with carbohydrate, protein and fat-what is possible, what is not? Nutrients 2012;4(09):1187-1212

36 Rowbottom DG, Green KJ. Acute exercise effects on the immune system. Med Sci Sports Exerc 2000;32(7, Suppl):S396-S405

37 Gleeson M. Immune function in sport and exercise. J Appl Physiol (1985) 2007;103(02):693-699

38 Catanho da Silva FO, Macedo DV. Physical exercise, inflammatory process and adaptive condition: an overview. Braz J Kinanthropomet Hum Performance. 2011;13(04):320-328

39 Suzuki K, Naganuma S, Totsuka M, et al. Effects of exhaustive endurance exercise and its one-week daily repetition on neutrophil count and functional status in untrained men. Int J Sports Med 1996;17(03):205-212

40 Olgun N, Uysal KM, Irken G, et al. Platelet activation in congenital heart diseases. Acta Paediatr Jpn 1997;39(05):566-569

$41 \mathrm{Wu}$ KK. Hemostatic tests in the prediction of atherothrombotic disease. Int J Clin Lab Res 1997;27(03):145-152

42 Davis RB, Boyd DG, McKinney ME, Jones CC. Effects of exercise and exercise conditioning on blood platelet function. Med Sci Sports Exerc 1990;22(01):49-53

43 Kestin AS, Ellis PA, Barnard MR, Errichetti A, Rosner BA, Michelson AD. Effect of strenuous exercise on platelet activation state and reactivity. Circulation 1993;88(4 Pt 1):1502-1511

44 Wang JS, Jen CJ, Chen HI. Effects of exercise training and deconditioning on platelet function in men. Arterioscler Thromb Vasc Biol 1995;15(10):1668-1674

45 Ponjee GA, Janssen GM, van Wersch JW. Prolonged endurance exercise and blood coagulation: a 9 month prospective study. Blood Coagul Fibrinolysis 1993;4(01):21-25

46 Gonzales F, Mañas M, Seiquer I, et al. Blood platelet function in healthy individuals of different ages. Effects of exercise and exercise conditioning. J Sports Med Phys Fitness 1996;36(02): $112-116$

47 Creighton BC, Kupchak BR, Aristizabal JC, et al. Influence of training on markers of platelet activation in response to a bout of heavy resistance exercise. Eur J Appl Physiol 2013;113(09): 2203-2209

48 Murakami T, Komiyama Y, Masuda M, et al. Flow cytometric analysis of platelet activation markers CD62P and CD63 in patients with coronary artery disease. Eur J Clin Invest 1996; 26(11):996-1003 
49 Roest M, van Holten TC, Fleurke GJ, Remijn JA. Platelet activation test in unprocessed blood (Pac-t-UB) to monitor platelet concentrates and whole blood of thrombocytopenic patients. Transfus Med Hemother 2013;40(02):117-125

50 Ferguson EW, Bernier LL, Banta GR, Yu-Yahiro J, Schoomaker EB. Effects of exercise and conditioning on clotting and fibrinolytic activity in men. J Appl Physiol (1985) 1987;62(04):1416-1421

51 Watts EJ. Haemostatic changes in long-distance runners and their relevance to the prevention of ischaemic heart disease. Blood Coagul Fibrinolysis 1991;2(02):221-225

52 El-Sayed MS, Lin X, Rattu AJ. Blood coagulation and fibrinolysis at rest and in response to maximal exercise before and after a physical conditioning programme. Blood Coagul Fibrinolysis 1995;6(08):747-752

53 Korsan-Bengtsen K, Wilhelmsen L, Tibblin G. Blood coagulation and fibrinolysis in relation to degree of physical activity during work and leisure time. A study based on a random sample of 54year-old men. Acta Med Scand 1973;193(1-2):73-77

54 Hilberg T, Menzel K, Wehmeier UF. Endurance training modifies exercise-induced activation of blood coagulation: RCT. Eur J Appl Physiol 2013;113(06):1423-1430

55 Kupchak BR, Creighton BC, Aristizabal JC, et al. Beneficial effects of habitual resistance exercise training on coagulation and fibrinolytic responses. Thromb Res 2013;131(06):e227-e234

56 Wagner DD. Cell biology of von Willebrand factor. Annu Rev Cell Biol 1990;6:217-246

57 Spiel AO, Gilbert JC, Jilma B. von Willebrand factor in cardiovascular disease: focus on acute coronary syndromes. Circulation 2008;117(11):1449-1459

58 Pinsky DJ, Naka Y, Liao $\mathrm{H}$, et al. Hypoxia-induced exocytosis of endothelial cell Weibel-Palade bodies. A mechanism for rapid neutrophil recruitment after cardiac preservation. J Clin Invest 1996;97(02):493-500

59 El-Sayed MS, Sale C, Jones PG, Chester M. Blood hemostasis in exercise and training. Med Sci Sports Exerc 2000;32(05):918-925

60 van Loon JE, Sonneveld MA, Praet SF, de Maat MP, Leebeek FW. Performance related factors are the main determinants of the von Willebrand factor response to exhaustive physical exercise. PLoS One 2014;9(03):e91687

61 Stakiw J, Bowman M, Hegadorn C, et al. The effect of exercise on von Willebrand factor and ADAMTS- 13 in individuals with type 1 and type 2B von Willebrand disease. J Thromb Haemost 2008;6 (01):90-96

62 van Mourik JA, Boertjes R, Huisveld IA, et al. von Willebrand factor propeptide in vascular disorders: a tool to distinguish between acute and chronic endothelial cell perturbation. Blood 1999;94(01):179-185

63 Green DJ, Maiorana A, O'Driscoll G, Taylor R. Effect of exercise training on endothelium-derived nitric oxide function in humans. J Physiol 2004;561(Pt 1):1-25

64 Lippi G, Salvagno GL, Montagana M, Guidi GC. Chronic influence of vigorous aerobic training on hemostasis. Blood Coagul Fibrinolysis 2005;16(07):533-534

65 Wang JS, Li YS, Chen JC, Chen YW. Effects of exercise training and deconditioning on platelet aggregation induced by alternating shear stress in men. Arterioscler Thromb Vasc Biol 2005;25(02):454-460

66 von Känel R, Dimsdale JE. Effects of sympathetic activation by adrenergic infusions on hemostasis in vivo. Eur J Haematol 2000; 65(06):357-369

67 Sadler JE. Low von Willebrand factor: sometimes a risk factor and sometimes a disease. Hematology (Am Soc Hematol Educ Program) 2009:106-112

68 Goto S, Ikeda Y, Murata M, et al. Epinephrine augments von Willebrand factor-dependent shear-induced platelet aggregation. Circulation 1992;86(06):1859-1863

69 Tomasiak M, Stelmach H, Rusak T, Ciborowski M, Radziwon P. Vasopressin acts on platelets to generate procoagulant activity. Blood Coagul Fibrinolysis 2008;19(07):615-624
70 Delp MD, O'Leary DS. Integrative control of the skeletal muscle microcirculation in the maintenance of arterial pressure during exercise. J Appl Physiol (1985) 2004;97(03):1112-1118

71 Small M, Tweddel AC, Rankin AC, Lowe GD, Prentice CR, Forbes $\mathrm{CD}$. Blood coagulation and platelet function following maximal exercise: effects of beta-adrenoceptor blockade. Haemostasis 1984;14(03):262-268

72 Huizinga EG, Tsuji S, Romijn RA, et al. Structures of glycoprotein Ibalpha and its complex with von Willebrand factor A1 domain. Science 2002;297(5584):1176-1179

73 Ruggeri ZM. The role of von Willebrand factor in thrombus formation. Thromb Res 2007;120(Suppl 1):S5-S9

74 Savage B, Saldívar E, Ruggeri ZM. Initiation of platelet adhesion by arrest onto fibrinogen or translocation on von Willebrand factor. Cell 1996;84(02):289-297

75 Mazzeo RS. Catecholamine responses to acute and chronic exercise. Med Sci Sports Exerc 1991;23(07):839-845

76 Boman K, Hellsten G, Bruce A, Hallmans G, Nilsson TK. Endurance physical activity, diet and fibrinolysis. Atherosclerosis 1994;106 (01):65-74

77 Rankinen T, Rauramaa R, Vaisanen S, Halonen P, Penttila IM. Blood coagulation and fibrinolytic factors are unchanged by aerobic exercise or fat modified diet. Fibrinolysis 1994;8:48-53

78 van den Burg PJ, Hospers JE, van Vliet M, Mosterd WL, Bouma BN, Huisveld IA. Effect of endurance training and seasonal fluctuation on coagulation and fibrinolysis in young sedentary men. J Appl Physiol (1985) 1997;82(02):613-620

79 Lockard MM, Gopinathannair R, Paton CM, Phares DA, Hagberg JM. Exercise training-induced changes in coagulation factors in older adults. Med Sci Sports Exerc 2007;39(04):587-592

80 Womack CJ, Nagelkirk PR, Coughlin AM. Exercise-induced changes in coagulation and fibrinolysis in healthy populations and patients with cardiovascular disease. Sports Med 2003;33(11):795-807

81 Hegde SS, Goldfarb AH, Hegde S. Clotting and fibrinolytic activity change during the $1 \mathrm{~h}$ after a submaximal run. Med Sci Sports Exerc 2001;33(06):887-892

82 Posthuma JJ, Loeffen R, van Oerle R, et al. Long-term strenuous exercise induces a hypercoagulable state through contact activation. Thromb Haemost 2014;111(06):1197-1199

83 Hemker HC, Giesen P, Al Dieri R, et al. Calibrated automated thrombin generation measurement in clotting plasma. Pathophysiol Haemost Thromb 2003;33(01):4-15

84 Szymanski LM, Pate RR, Durstine JL. Effects of maximal exercise and venous occlusion on fibrinolytic activity in physically active and inactive men. J Appl Physiol (1985) 1994;77(05):2305-2310

85 Stratton JR, Chandler WL, Schwartz RS, et al. Effects of physical conditioning on fibrinolytic variables and fibrinogen in young and old healthy adults. Circulation 1991;83(05):1692-1697

86 Mosesson MW, Siebenlist KR, Meh DA. The structure and biological features of fibrinogen and fibrin. Ann N Y Acad Sci 2001; 936:11-30

87 Ribeiro J, Almeida-Dias A, Ascensão A, et al. Hemostatic response to acute physical exercise in healthy adolescents. J Sci Med Sport 2007;10(03):164-169

88 Smith JE. Effects of strenuous exercise on haemostasis. Br J Sports Med 2003;37(05):433-435

89 Szymanski LM, Pate RR. Effects of exercise intensity, duration, and time of day on fibrinolytic activity in physically active men. Med Sci Sports Exerc 1994;26(09):1102-1108

90 El-Sayed MS. Effects of high and low intensity aerobic conditioning programs on blood fibrinolysis and lipid profile. Blood Coagul Fibrinolysis 1996;7(04):484-490

91 El-Sayed MS. Effects of exercise on blood coagulation, fibrinolysis and platelet aggregation. Sports Med 1996;22(05):282-298

92 Schuit AJ, Schouten EG, Kluft C, de Maat M, Menheere PP, Kok FJ. Effect of strenuous exercise on fibrinogen and fibrinolysis in healthy elderly men and women. Thromb Haemost 1997;78(02): 845-851 
93 DeSouza CA, Jones PP, Seals DR. Physical activity status and adverse age-related differences in coagulation and fibrinolytic factors in women. Arterioscler Thromb Vasc Biol 1998;18(03):362-368

94 Leon AS, Myers MJ, Connett J. Leisure time physical activity and the 16-year risks of mortality from coronary heart disease and all-causes in the Multiple Risk Factor Intervention Trial (MRFIT). Int J Sports Med 1997;18(Suppl 3):S208-S215

95 McMurray RG, Ainsworth BE, Harrell JS, Griggs TR, Williams OD. Is physical activity or aerobic power more influential on reducing cardiovascular disease risk factors? Med Sci Sports Exerc 1998;30(10):1521-1529

96 Shaper AG, Wannamethee G, Weatherall R. Physical activity and ischaemic heart disease in middle-aged British men. Br Heart J 1991;66(05):384-394

97 Biggs R, MacFarlane RG, Pilling J. Observations on fibrinolysis; experimental activity produced by exercise or adrenaline. Lancet 1947;1(6448):402-405

98 Hansen JB, Wilsgård L, Olsen JO, Osterud B. Formation and persistence of procoagulant and fibrinolytic activities in circulation after strenuous physical exercise. Thromb Haemost 1990;64 (03):385-389

99 Röcker L, Taenzer M, Drygas WK, Lill H, Heyduck B, Altenkirch HU. Effect of prolonged physical exercise on the fibrinolytic system. Eur J Appl Physiol Occup Physiol 1990;60(06):478-481

100 De Paz JA, Lasierra J, Villa JG, Viladés E, Martín-Nuño MA, González-Gallego J. Changes in the fibrinolytic system associated with physical conditioning. Eur J Appl Physiol Occup Physiol 1992;65(05):388-393

101 de Geus EJ, Kluft C, de Bart AC, van Doornen LJ. Effects of exercise training on plasminogen activator inhibitor activity. Med Sci Sports Exerc 1992;24(11):1210-1219

102 Gris JC, Schved JF, Feugeas O, et al. Impact of smoking, physical training and weight reduction on FVII, PAI-1 and hemostatic markers in sedentary men. Thromb Haemost 1990;64(04):516-520

103 Speiser W, Langer W, Pschaick A, et al. Increased blood fibrinolytic activity after physical exercise: comparative study in individuals with different sporting activities and in patients after myocardial infarction taking part in a rehabilitation sports program. Thromb Res 1988;51(05):543-555

104 Estellés A, Aznar J, Tormo G, Sapena P, Tormo V, España F. Influence of a rehabilitation sports programme on the fibrinolytic activity of patients after myocardial infarction. Thromb Res 1989;55(02):203-212

105 Aird WC. Spatial and temporal dynamics of the endothelium. J Thromb Haemost 2005;3(07):1392-1406

106 de Boer A, Kluft C, Kroon JM, et al. Liver blood flow as a major determinant of the clearance of recombinant human tissue-type plasminogen activator. Thromb Haemost 1992;67(01):83-87

107 Chandler WL, Levy WC, Veith RC, Stratton JR. A kinetic model of the circulatory regulation of tissue plasminogen activator during exercise, epinephrine infusion, and endurance training. Blood 1993;81(12):3293-3302

108 Santilli F, Vazzana N, Iodice P, et al. Effects of high-amount-highintensity exercise on in vivo platelet activation: modulation by lipid peroxidation and AGE/RAGE axis. Thromb Haemost 2013; 110(06):1232-1240

109 Nofer JR, Walter M, Kehrel B, et al. HDL3-mediated inhibition of thrombin-induced platelet aggregation and fibrinogen binding occurs via decreased production of phosphoinositide-derived second messengers 1,2-diacylglycerol and inositol 1,4,5-tris-phosphate. Arterioscler Thromb Vasc Biol 1998;18(06):861-869

110 Barlow CE, Defina LF, Radford NB, et al. Cardiorespiratory fitness and long-term survival in "low-risk" adults. J Am Heart Assoc 2012;1(04):e001354

111 Kjaer M, Secher NH, Galbo H. Physical stress and catecholamine release. Baillieres Clin Endocrinol Metab 1987;1(02):279-298

112 Cadroy Y, Pillard F, Sakariassen KS, Thalamas C, Boneu B, Riviere D. Strenuous but not moderate exercise increases the thrombotic tendency in healthy sedentary male volunteers. J Appl Physiol (1985) 2002;93(03):829-833

113 Chen YW, Apostolakis S, Lip GY. Exercise-induced changes in inflammatory processes: implications for thrombogenesis in cardiovascular disease. Ann Med 2014;46(07):439-455

114 Kargotich S, Goodman C, Keast D, Morton AR. The influence of exercise-induced plasma volume changes on the interpretation of biochemical parameters used for monitoring exercise, training and sport. Sports Med 1998;26(02):101-117

115 Andrew M, Carter C, O'Brodovich H, Heigenhauser G. Increases in factor VIII complex and fibrinolytic activity are dependent on exercise intensity. J Appl Physiol (1985) 1986;60(06):1917-1922

116 Cohen RJ, Epstein SE, Cohen LS, Dennis LH. Alterations of fibrinolysis and blood coagulation induced by exercise, and the role of beta-adrenergic-receptor stimulation. Lancet 1968; 2(7581):1264-1266

117 Iatridis SG, Ferguson JH. Effect of physical exercise on blood clotting and fibrinolysis. J Appl Physiol 1963;18:337-344

118 Bourey RE, Santoro SA. Interactions of exercise, coagulation, platelets, and fibrinolysis-a brief review. Med Sci Sports Exerc 1988;20(05):439-446

119 Gawel MJ, Glover V, Burkitt M, Sandler M, Rose FC. The specific activity of platelet monoamine oxidase varies with platelet count during severe exercise and noradrenaline infusion. Psychopharmacology (Berl) 1981;72(03):275-277

120 Haber P, Silberbauer K, Sinzinger H. Quantitative studies on reversible thrombocyte aggregation during exertion [in German]. Schweiz Med Wochenschr 1980;110(41):1488-1491

121 Rakobowchuk M, McGowan CL, de Groot PC, Hartman JW, Phillips SM, MacDonald MJ. Endothelial function of young healthy males following whole body resistance training. J Appl Physiol (1985) 2005;98(06):2185-2190

122 Hilberg T, Nowacki PE, Müller-Berghaus G, Gabriel HH. Changes in blood coagulation and fibrinolysis associated with maximal exercise and physical conditioning in women taking low dose oral contraceptives. J Sci Med Sport 2000;3(04):383-390

123 Kahraman S, Bediz CS, Pişkin O, et al. The effect of the acute submaximal exercise on thrombin activatable fibrinolysis inhibitor levels in young sedentary males. Clin Appl Thromb Hemost 2011;17(04):414-420

124 Sand KL, Flatebo T, Andersen MB, Maghazachi AA. Effects of exercise on leukocytosis and blood hemostasis in 800 healthy young females and males. World J Exp Med 2013;3(01):11-20

125 Kulaputana O, Macko RF, Ghiu I, Phares DA, Goldberg AP, Hagberg JM. Human gender differences in fibrinolytic responses to exercise training and their determinants. Exp Physiol 2005;90(06): 881-887

126 Ninivaggi M, de Laat M, Lancé MM, et al. Hypoxia induces a prothrombotic state independently of the physical activity. PLoS One 2015;10(10):e0141797

127 Huskens D, Roest M, Remijn JA, et al. Strenuous exercise induces a hyperreactive rebalanced haemostatic state that is more pronounced in men. Thromb Haemost 2016;115(06):1109-1119

128 Bloemen S, Huskens D, Konings J, et al. Interindividual variability and normal ranges of whole blood and plasma thrombin generation. J Appl Laboratory Med 2017;2(02):150-164

129 Huskens D, Sang Y, Konings J, et al. Standardization and reference ranges for whole blood platelet function measurements using a flow cytometric platelet activation test. PLoS One 2018;13(02): e0192079

130 Hulstein JJ, de Groot PG, Silence K, Veyradier A, Fijnheer R, Lenting PJ. A novel nanobody that detects the gain-of-function phenotype of von Willebrand factor in ADAMTS13 deficiency and von Willebrand disease type 2B. Blood 2005;106(09): 3035-3042

131 Cimenti C, Schlagenhauf A, Leschnik B, et al. Low endogenous thrombin potential in trained subjects. Thromb Res 2013;131 (06):e281-e285 


\section{Appendix: Methodology for the Pilot Study}

\section{Study Population}

Five physically fit (nonprofessional) male cyclists were included in the pilot study and cycled $80 \mathrm{~km}$ on each of three consecutive days. All participants were nonsmokers, none had a known hemostatic or cardiovascular disease, and none used antiplatelet/anticoagulant drugs for 1 week prior to the study. All participants gave written informed consent before the study and blood withdrawal was approved by the medical research ethics committee of Maastricht University Medical Centre.

\section{Repetitive Exercise}

On each of three subsequent days, the participants cycled approximately $80 \mathrm{~km}$ over the course of 4 hours, always at the same time of day to take into account possible diurnal effects. $^{24}$ Submaximal exercise intensity was achieved by cycling in a hilly landscape, covering a total of 800 height meters, with a maximum slope of $10 \%$, inducing 90 to $95 \%$ intensity for approximately 10 minutes when climbing hills, and $>75 \%$ intensity between hills.

\section{Blood Sample Collection}

Blood samples were collected before and immediately after exercise on each of the three study days. Venous blood was collected in $3.2 \%(\mathrm{w} / \mathrm{v})$ citrated Vacutainer tubes (Becton Dickinson (BD) Vacutainer System).

\section{Analytical Methods}

To characterize changes in their hemostatic profile, we measured VWF (total antigen, ${ }^{126}$ VWF propeptide, ${ }^{62}$ and active VWF) levels, FVIII, ${ }^{126,127}$ thrombin generation, ${ }^{128}$ fibrinogen levels, ${ }^{127}$ platelet activation, ${ }^{129}$ and clot lysis time $^{127}$ (methods according to references). Peripheral blood cell counts in citrated whole blood were determined using a
COULTER counter analyzer (Beckman Coulter, Woerden, the Netherlands). Since the active VWF and VWF:Ag assays as used in our laboratory have not been published before, they are described in detail below.

\section{Active VWF and VWF:Ag Assays}

VWF:Ag and active VWF were measured in plasma by enzyme-linked immunosorbent assays (ELISAs). The active VWF assay is based on a llama-derived variable heavy chain (VHH) directed against the A1 domain of VWF, which is only exposed upon unfolding of VWF. ${ }^{130}$ Briefly, 96 wells microtiter plates (NUNC Maxisorp, Thermo Fisher Scientific, USA) were coated overnight at $4^{\circ} \mathrm{C}$ with VHH against active VWF or with polyclonal antibody against human VWF (A0082, Dako, Denmark) (VWF:Ag) and blocked with $2 \%$ bovine serum albumin (BSA; Sigma, USA) in phosphate-buffered saline (PBS) for 45 minutes at room temperature. After extensive washing with $0.01 \%$ Tween-20 in PBS, plasma samples (diluted in PBS/ $1 \%$ BSA) were incubated for 2 hours at room temperature. Following another round of washing, the wells were incubated with horseradish peroxidase (HRP)-conjugated polyclonal anti-VWF (P0226, Dako, Denmark) in PBS/1\% BSA for 2 hours at room temperature. Plates were then washed three times more before measuring the binding of active VWF to the $\mathrm{VHH}$ or VWF:Ag to the polyclonal anti-VWF antibodies by using SIGMAFAST OPD (Sigma, USA) as a substrate for HRP. The substrate reaction was stopped with $3 \mathrm{M}$ sulfuric acid $\left(\mathrm{H}_{2} \mathrm{SO}_{4}\right.$, Aldrich, USA). Optical densities (ODs) were measured at $490 \mathrm{~nm}$ using an ELx808 Absorbance Microplate Reader (Biotek, USA). Normal pooled plasma (NPP) was used as a standard in every plate and plasma sample results were normalized (\%) to NPP on the same plate. The results of these analyses are described below each corresponding figure, as referred to in the main text of this review. 